\title{
Female leadership, parental non-involvement, teenage pregnancy and poverty impact on underperformance of learners in the further education and training
}

\begin{tabular}{|c|c|}
\hline \multicolumn{2}{|c|}{$\begin{array}{l}\text { Authors: } \\
\text { Cheryl Potgieter }{ }^{1} \text { ( } \\
\text { Nelisiwe Zuma }\end{array}$} \\
\hline \multicolumn{2}{|c|}{$\begin{array}{l}\text { Affiliations: } \\
{ }^{1} \text { Head of Research Focus Area } \\
\text { Gender Justice, Health and } \\
\text { Human Development in the } \\
\text { office of the DVC Research, } \\
\text { Innovation and Engagement, } \\
\text { Faculty of Arts and Design, } \\
\text { Durban University of } \\
\text { Technology, Durban, } \\
\text { South Africa }\end{array}$} \\
\hline \multicolumn{2}{|c|}{$\begin{array}{l}\text { 2Department of Education, } \\
\text { Faculty of Arts and Design, } \\
\text { Durban University of } \\
\text { Technology, Durban, } \\
\text { South Africa }\end{array}$} \\
\hline \multicolumn{2}{|c|}{$\begin{array}{l}\text { Corresponding author: } \\
\text { Cheryl Potgieter, } \\
\text { cherylp1@dut.ac.za }\end{array}$} \\
\hline \multicolumn{2}{|c|}{$\begin{array}{l}\text { Dates: } \\
\text { Received: } 27 \text { Sept. } 2019 \\
\text { Accepted: } 13 \text { Oct. } 2019 \\
\text { Published: } 05 \text { Dec. } 2019\end{array}$} \\
\hline \multicolumn{2}{|c|}{$\begin{array}{l}\text { How to cite this article: } \\
\text { Potgieter, C. \& Zuma, N., 2019, } \\
\text { 'Female leadership, parental } \\
\text { non-involvement, teenage } \\
\text { pregnancy and poverty impact } \\
\text { on underperformance of } \\
\text { learners in the further } \\
\text { education and training', HTS } \\
\text { Teologiese Studies/Theological } \\
\text { Studies } 75(4), \text { a5826. } \\
\text { https://doi.org/10.4102/hts. } \\
\text { v75i4.5826 }\end{array}$} \\
\hline \multicolumn{2}{|c|}{$\begin{array}{l}\text { Copyright: } \\
\text { (c) 2019. The Authors. } \\
\text { Licensee: AOSIS. This work } \\
\text { is licensed under the } \\
\text { Creative Commons } \\
\text { Attribution License. }\end{array}$} \\
\hline \multirow{2}{*}{ 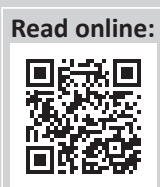 } & \\
\hline & $\begin{array}{l}\text { Scan this QR } \\
\text { code with your } \\
\text { smart phone or } \\
\text { mobile device } \\
\text { to read online. }\end{array}$ \\
\hline
\end{tabular}

A number of studies have explored the underperformance of learners. However, there is a paucity of research in South Africa, which focuses primarily on how school leadership, commonly referred to as school management teams (SMTs), accounts for the underperformance of learners and thus the underperformance of schools. To fill this gap, the current study, undertaken in two schools in a district in KwaZulu-Natal province, aimed to explore through a qualitative approach the opinions of SMTs regarding underperformance in the further education and training (FET) phase. School management teams were interviewed using a semi-structured interview guide and in-depth face-to-face interviews. The interview guideline had a set of broad flexibly worded questions that allowed for in-depth discussion. Data were analysed using a thematic data analysis method. The school management team accounted for, and linked underperformance to a range of reasons. In this article, we present findings which emerged in relation to leadership weaknesses, particularly female leadership weaknesses, socio-economic challenges such as child-headed households and its consequences, teenage pregnancy, violence experienced by female learners, health of learners and educators and poverty. Systemic and structural societal challenges were flagged in the interviews as also impacting on the overall cognitive and psycho social development of learners. School management teams addressed the challenges by implementing a number of interventions that they reported were not successful. There is no simple answer to address the problem and we argue for a social compact which is inclusive of all stakeholders and suggest that intervening at the local level may not have a nationwide impact but it would have an impact on a particular school. Sensitivity training, which includes gender sensitivity training, and leadership training and support is suggested as part of the interventions. Certain best practices could then be shared with other schools which face similar challenges.

Keywords: underperformance of learners; school management teams; further education and training; gender and education; teenage pregnancy; poverty and underperformance; parental non-involvement; KZN schools.

\section{Introduction}

Underperforming schools and underperforming learners across the South African education system remain a challenging and serious problem for South Africa. Each year, the South African Department of Basic Education (DBE) releases a list of high schools that have a matric pass rate of $40 \%$ or lower for the preceding 5 years. At the beginning of 2019, 13 schools appeared on the list and all the schools were from either KwaZulu-Natal or Limpopo province (School Performance Report, DBE, 2018).

Underperforming schools that essentially include underperforming learners have major consequences for all including the school management teams (SMTs). It is a requirement of the South African Schools Act (84 of 1996) that each provincial education department has to, within the first 3 months after the matric results are released, indicate to the Education Minister how they plan to improve the performance of underperforming schools in particular (South African Schools Act, 84 of 1996).

Note: Special Collection Gender Justice, Health and Human Development, led by Cheryl Potgieter (Durban University of Technology). 
Essentially, a turnaround plan is required. The plan which has to be submitted is officially referred to as the academic performance improvement plan (APIP) and is the responsibility of the SMT which is led by the school principal. The SMT is thus assigned the role and responsibility of being the enabler and driver of producing learners who do not underperform and thus ensuring a school which is not classified as underperforming.

There is a growing body of research which provides evidence that learners across the system are underperforming. Chisholm (2011:50) points out that South African learners are not able to perform at the level expected of them from the foundation phase across various subjects. Chisholm (2011:53) states that: 'linguistic, race, class, culture and gender differences often compound the barriers to learning that learners face in the classroom'.

The majority of the underperforming schools and learners who underperform are based in townships and poor rural schools (see Department of Basic Education [DBE], NSC, School Performance Report 2019:18).

School management teams that play a crucial role in the success of the school are not always seen as effective. In a research conducted by Bayat, Louw and Rena (2014a:48), the following statement gives insight into how certain teachers view SMTs: '... SMTs lack adequate critical knowledge, technical capacity and are weak leaders and managers'.

In another study regarding SMTs in Gauteng, the primary aim was to explore common indigenous knowledge values that SMT and all stakeholders could possibly draw on to assist them in changing the culture of underperformance (Setlhodi-Mohapi \& Lebeloane 2014:475).

While there is research relating to SMTs there is a paucity in research, which explores the voices of SMTs in terms of how they account for underperformance. Essentially, there is limited research in terms of how SMTs in underperforming schools in South Africa account for underperformance.

However, an area even less researched is how SMTs account for underperformance not only in matric but in the overall FET band (grades 10-12). Matric is the end result of the FET band and if one could understand how leaders account for underperformance in this band, interventions could be implemented before grade 12 .

\section{Defining underperformance}

Many scholars do not provide a definition of 'underperformance of learners' but they contextualise their understanding. In South Africa, an underperforming school is a school that is unable to achieve a pass rate of $60 \%$ or more in the annual grade 12 national examinations.

Certain secondary schools have been labelled as underperforming schools because the matric pass rate in those schools is low. Taking the latter position to its logical conclusion it would be argued that a school with a low matric pass rate has a high percentage of underperforming learners. For this research, we have taken underperformance to include both underperforming schools (grade 12 pass rate less than 60\%) and underperforming learners.

\section{Research questions and objectives}

The objective of this study was to explore how SMTs account for the underperformance of learners in the further education training (FET) phase. The research was underpinned by the following research questions:

1. How do SMTs account for the underperformance of learners in the FET phase?

2. What interventions are required to assist underperforming learners to perform better in the FET phase?

3. What are the perceptions of SMTs regarding the challenges encountered by teachers in teaching underperforming learners?

\section{Methodology Site of research}

Two secondary schools in KwaZulu-Natal province were selected as case studies for the research. Schools A and B were officially classified as township schools and offered education from grades 8 to 12 . The learners lived in nearby townships where housing included low-cost government houses. Many of the families were dependent on the government's child support grants. Both schools had an enrolment of just over a 1000 learners. Although there were a few decent buildings in one of the schools, the majority of the infrastructure, services and facilities in both schools were inadequate to meet the needs of the entire staff and all learners.

The research utilised the case study method as it gave the researchers the space to be able to engage the participants' according to the research questions, in an exploratory and contextually relevant manner (Creswell 1994, 2003).

The research is underpinned by a feminist research paradigm. Feminist research is identified or underpinned, as stated by Burman (1994), by a:

[C]ommitment to a specific, feminist epistemology; that is, a theoretical and political analysis that critiques dominant conceptions of knowledge, and poses questions about the gendered orientation of, and criteria for, knowledge. (p. 124)

\section{Recruitment and profile participants}

Purposive sampling was utilised to identify participants. Purposive sampling allowed the researchers to select participants who were considered as good sources of information to respond to the aims and objectives of the study. The members of SMTs of these schools were selected because they, as participants, were considered valuable players in ensuring that the purpose and aims of the research were achieved (De Marrais \& Lapan 2004). 
Letters were sent to the principals of the schools requesting authorisation to conduct the research at their schools. Once permission was granted by the two schools, written communication was sent to individuals identified as part of SMTs in the FET phase and they were requested to participate in the study. A total of eight persons were interviewed for the research and the sample included six heads of departments and two deputy principals.

Six were men and two were women and they were aged between 41 and 50 years. Their length of service ranged between 13 and 29 years.

\section{Data collection}

\section{Instruments}

Two instruments, a biographical questionnaire and an interview guideline, were utilised to collect the data. The biographical questionnaire obtained respondents' profiles and backgrounds which included information relating to their qualifications, teaching experience, gender and age. The interviews were conducted both in English and Zulu and the participants chose to move between English and Zulu although all were native Zulu speakers. A reason for the latter was that most of the educators spoke both languages on a daily basis and the school programme was delivered in English. All the interviews were transcribed verbatim (Zulu and English) and the conversations in Zulu (which were limited) were translated into English. The interview guideline that was developed comprised a list of questions which elicited information in relation to the objectives of the study. The interview guideline consisted of core questions and subsidiary questions which together formed a structured plan to collect information.

An interview guideline, and not interview schedule, was developed as it allows for more flexibility in the interviews. The list of pre-determined questions acted as a guide to initiate and guide the face-to-face interviews and there was also space to accommodate questions and discussions that emerged during the interview.

The participants gave written permission for the interviews to be recorded and all the necessary forms to be filled out, which also took care of issues related to confidentiality. At the beginning of the interview, the researcher explained to each participant the ethical issues that guided the interview. The participants were informed that even though the interview would be recorded, personal details would remain confidential.

\section{Data analysis}

The interviews were analysed utilising a thematic analysis approach.

Thematic analysis is a tool that provides an 'accessible and flexible' approach to analysing a data set (Braun \& Clarke 2006). Themes were not pre-determined and emerged as data were analysed. The interviews were transcribed verbatim.
Data obtained were thematically analysed from the transcripts and a number of themes emerged which included the broad overall themes of underperformance because of systems and policy shortcomings, underperformance because of weak leadership and underperformance due to socio-economic reasons. Each of the latter broad themes included a number of sub-themes. In this article, only the broad themes and the related sub-themes linked to leadership and socio-economic reasons for underperformance are presented and engaged with, as the focus in the publication is on gender justice, health and development. It is an extensive study and another publication will reflect the additional findings that emerged.

\section{Ethical consideration}

The KwaZulu-Natal Department of Education ethics committee (REF: 2/4/8/1/72) and a university ethics committee approved the research (protocol reference number: HSS/0114/014). The research complied with the ethical standards, principles and procedures as required by the ethics committees. These principles included issues of confidentiality such as obtaining signed consent forms from participants and safe storage of confidential information.

\section{Results and discussion Female leadership constructed as a weak leadership}

The female principal who had been in the position for the past 2 years at one of the schools was singled out as responsible for underperformance of the school and the learners. The discourse emerged that weak leadership was a factor leading to underperformance. However, it was particularly gendered - while there was recognition that the school and the learners were underperforming under the previous male principal, he was not blamed but issues of infrastructure were listed as the challenges.

It was pointed out that the infrastructure and other problems were the same as under the previous male principal; yet, he was not blamed. A discourse emerged that she was expected to 'do better' and underperformance of the school was linked to her being incompetent.

A participant stated:

'The leadership she presented after obtaining the position proved that she was incompetent and could not deal with the issue involving teaching and learning.' (2015)

Another participant supported the latter discourse:

'We had a crisis in 2013 when the pass rate dropped to $45 \%$. Our principal ... Inexperienced and not a good leader. Due to her incompetency the school ... is in a state of falling apart.'

Yet another participant said:

This dropping of the pass rate was due to the change of the principal. I can say that the new principal did not have good leadership skills and her incompetency had a negative impact on the performance of learners in matric and the school as a whole. 
The participants who were interviewed had many years of teaching experience and were mostly men.

Interestingly, the female principal was constructed as younger than the participants and she was seen to lack experience and competence. When probed further, there was no doubt that the school principal was in the same age range as that of the SMT.

There is no doubt that weak leadership contributes to underperformance and underperforming schools.

However, although under the male principal's leadership the school was underperforming, he was not held responsible or viewed as incompetent. Rather, infrastructure, lack of resources and pupils not doing their work were how the participants accounted for the underperformance when led by the male principal. The SMT members who were interviewed chose not to be part of the female principal's 'inner circle'. They blamed her for favouring certain staff members and they were not 'enthusiastic' in providing her with support even though they were part of the leadership team who had to account to the DBE.

If one does not 'shine' a gender lens on the conversation it could be overlooked as just a leadership incompetency challenge. The blaming of women in their 'personal capacity' for underperformance could have far reaching-consequences for women leadership in schools as women may not choose to take these positions or once in these positions the space is so 'chilly' that they step down.

The interviewees were thus tacitly suggesting that because the leader is female she is expected to be a weak leader and this was one of the reasons for the school not reaching its full potential. It was insinuated by male participants that she was appointed because of 'gender equality' which was a code word for 'she does not deserve to be holding the position'.

There is no doubt that weak leadership leads to underperformance and the works of researchers such as Bayat et al. (2014a); Bayat, Louw and Rena (2014b); Louis, Dretzke and Wahlstrom (2010); Mphale and Mhlauli (2014) all support this point. However, it has emerged from this research that the gender of the principal was a fundamental factor that contributed to the SMT blaming her 'personally' for the underperformance. They overlooked or downplayed the fact that infrastructure and resources were a challenge as it was even when the previous principal was in office, but they expected her to deliver and excel irrespective of the fact that the conditions had not changed.

As a woman leader, she was expected to almost 'be a magician'. Diversity is important and women leadership has to be supported as many women step down because of lack of support. It is very interesting, but not surprising that this gendered bias has emerged and it indicates the need to provide support for women leaders. In addition, all staff, including the
SMT, needs to be exposed to gender sensitivity and gender awareness workshops and courses which would raise their consciousness in relation to accepting female leadership.

\section{Underperformance, teenage pregnancy and violence}

It emerged from the conversations that members of the SMT viewed what they labelled socio-economic challenges as leading to underperformance.

Male and female interviewees spoke about the abuse of learners both at home and in society and how it was affecting their performance at school.

As one of the participants stated:

'[... S ]ome learners are unable to do their schoolwork because they live with abusive parents, who could be a stepmother, uncle or guardian like a foster parent. Some female learners are experiencing rape at home and so do not do their schoolwork because of trauma. It affects their health mental health and health.'

\section{Participant K further asserted that:}

'... Children may not be playful or troublesome but are hindered by the problems that they have at home from doing their schoolwork. Those problems could be abusive uncles, alcohol and substance abuse by parents or even and often rape.'

Literature indicates that abuse and domestic violence have a negative impact on the cognitive skills and the overall psychosocial skills of children of all ages (Harper et al. 2018:2512-2536). Participants also spoke of the fact that many of the young girls who were raped became pregnant and were often traumatised and could not concentrate on their school work or were not interested as they would anyways be leaving school to give birth to a baby. Educators and researchers have documented their concerns and perceptions of teenage pregnancy on learners in South African Schools (Malahlela \& Chireshe 2013:137-148).

South Africa has an exceptionally high rate of teenagers and pre-teens giving birth. In a live birth report commissioned by Stats SA (2018), 3261 girls between the ages of 10 and 14 years were registered as mothers in 2017. Thus, in 2017, teenagers accounted for $10 \%$ of all deliveries in South Africa.

KwaZulu-Natal province had the highest teenage pregnancy rate in the country when the data were collected and also the highest rate of HIV and (sexual transmitted infections [STI]) in the age group 16-35 years.

The participants interviewed recognised that often the female learners are blamed as it was an easy 'solution' but were aware that boys and men were abusing female learners and it had become normative.

The SMT strongly felt that perpetrators had to feel the full brunt of the law. It also emerged that the female learners underperformed as they were pregnant or often did not 
have money to take care of regular health issues. Regular health issues referred to the females not having money to buy sanitary pads or even pain killers when they were menstruating. Not being able to manage menstrual health has been recognised by researchers and governments and there is a policy and interventions in relation to menstrual health management (Sommer et al. 2014:589).

Challenges with menstrual hygiene management (MHM) have a number of consequences; one being absenteeism and a consequence therefore is not performing academically (Chikulo 2015).

However, often when the education department talks about underperformance or has to deal with underperforming schools, these challenges faced by women are not linked to the underperformance. There seems to be a disjuncture between policies that recognise these challenges and a discourse that emerges when matric results are released and schools underperform.

The following public speech by the KZN health minister (even though it may be unintentional) shifts the blame of teenage pregnancies to girls and parents (Ndlovu 2018):

I wish to appeal to you as the community to raising our children with correct values. Discourage daughters from becoming pregnant in their teens as it is detrimental to their futures (Dr Sibongiseni Ndlovu, Zululand Observer, 28 February 2018).

Members of the SMTs challenged the type of sentiment of the minister and suggested that girls should not be blamed. They recognised that power relationships between boys and girls and between older men and the girls often led to the girls being abused by their male peers and older men.

In addition, the SMTs were aware that many male and female learners were sick and lacked access to health care. The learners' overall health was an often overlooked factor in account of learners' underperformance.

It was pointed out that infrastructure, policies and school resources have to be addressed but if the girls are having babies while still in the FET phase, and rates of HIV and STI are increasing the issues of health, gender and poverty need to be addressed by the education department and government.

\section{Child-headed households, poverty and underperformance}

A dominant theme that arose was the impact of povertystricken child-headed households.

The following verbatim excerpts capture the challenge:

\begin{abstract}
'Maybe a child is coming from a child headed family and so is unable to maintain a balance between the role of parenting himself or herself and the other young ones at home and also being a schoolchild that must study and do some homework as well.'
\end{abstract}

There are also some cases of child headed families where a child takes the role of a mother or father to support younger sisters and brothers. They end up not having time for schoolwork because such children need to consider seeking for piece jobs in order to support their families.

To make a living after school and on weekends, boys work as money collectors with taxi services or as driver assistants collecting money and calling for passengers to take their tax. They work at car washing stations as well.

Girls work as babysitters fetching toddlers and babies from day care centres or families until parents return from work. Girls also work as piece work domestic workers where they do some washing, ironing and cleaning as a means of getting money to support their families.

It is common to find a child coming from a child headed household not doing his or her homework.

Sometimes not because they did not want to, but because there was no electricity at home, no food or a child was not at home doing some piece work ... boys work at car wash sites ... they also become beggars for money on city streets. Girls work as domestic workers doing washing, ironing and cooking. Our educators take the active role of acting as social workers to try to deal with these challenges (M).

(M) also cited that learners from child-headed households lack basic needs, such as food and electricity, which are required for improved academic success. There is no doubt that basic needs have to be met for learners to succeed.

It is clear that these learners in the FET phase (grades 10-12) have responsibilities at par with adults.

While child labour has decreased in South Africa, it still exists. In 2015, approximately 577000 children aged 7-17 years were reported to be involved in child labour, a decrease of 1.9\% since 2010 (Statistics South Africa 2015).

Children in KwaZulu-Natal province (10\%) had a higher chance of being involved in child labour compared to other provinces. The data thus support the SMTs we interviewed on account of child labour (Statistics South Africa 2015).

It is often argued that education is a way out of poverty but these children cannot fully avail school opportunities as they are occupied with the needs of the stomach and basic survival.

Child headed households are often the result of the adults falling sick and dying and are thus a fundamental contributing factor to underperformance (Newlin, Reynold \& Nombutho 2017).

In addition it emerged that SMT members were aware that the learners who were underperforming often lived in overcrowded households with many adults and children. 
The 2018 General Household Survey conducted by Statistics South Africa supports the participants' views as it indicated that KwaZulu-Natal had the largest household size amongst all the provinces in the country (20.3\%), having a household size of six or more people compared with the national average of $13.6 \%$.

The survey also indicted that KwaZulu-Natal has the highest percentage of households where one parent has died. Men have a higher incidence of dying in the province and this translates into KwaZulu-Natal having the highest percentage of households in the country headed by women $(49.8 \%)$ compared with the national average of $43.1 \%$.

Participants' views suggested that poor performance in class assessments occurs because learners are not serious about schoolwork and sick and tired most of the time and it is played out as being lazy. However, the social conditions are leading to the 'laziness' and it is not because of a problematic work ethic.

The SMT pointed out that the learner's living conditions impacted learners not doing homework and not submitting assessment tasks and that contributed to underperformance as often various points of evaluation were taken into account. It was pointed out that SMTs as teachers and leaders often suggest that learners are lazy. SMT members are frustrated and shift the blame to learners. However, the learners were not necessarily lazy but could be tired and demotivated.

The participants in the study conducted by Dimmitt (2003), who included learners, parents and teachers, all identified not doing homework as the main reason for not passing certain grades.

Although participants in our study sometimes blamed learners, they showed insight into broader issues such as the weak education in earlier grades. Grades 7-9 were often mentioned. At this early phase, learners, often, because of factors beyond their control do not prioritise homework as they possibly have household and other adult responsibilities. Often these learners are in the FET phase, but they lack the necessary background of concepts taught in the general education and training (GET) phase.

\section{Health and well-being of educators and leadership}

The participants were concerned that their workload increases because they have to conduct extra classes for underperforming learners. At the same time, the underperforming learners showed no interest in the additional classes planned for them since in most cases they bunk these extra classes because of having other issues to take care of. An alternative explanation is that they are just disillusioned.

Participants felt that it is demotivating to plan extra lessons that increase their workloads that underperforming learners never bother to attend. The participants indicated that this impacted educator's motivation and also health. Often teachers had to deal with students who were angry and violent towards each other and towards the teachers.

The SMT indicated that all stakeholders were affected. The teachers and the SMT who are also essentially teachers were stressed and burnt out and it led to a high level of teacher absenteeism

It is clear that the educators, SMT, learners and parents suffer trauma because of systemic and structural changes. Essentially, poverty, inequality and unemployment, which often translate into interpersonal and intergroup violence, have an impact on underperformance.

\section{Parental non-involvement and underperformance}

The following excerpts indicate that SMTs, while acknowledging the social context of parents and children often, when accounting for lack of parental involvement and its impacton underperformance, offer a very decontextualised discourse:

\begin{abstract}
'The first part is the lack of support from the parents. My personal view is that we are having a problem especially in township schools because parents are not actively involved in the education matters of their children. Accordingly, parents are not there, they are not helping their children. Children are not getting support at home. The educators are doing their part at school to teach learners but at home, learners do not get support from parents or guardians. You find that educators push and push, but once learners are out of school, no one supports them. At home, no one pushes learners to come to school. Even when the school calls parents' meetings, parents do not show up, they do not come.' (M, 2015)
\end{abstract}

It is important that the views of parents in terms of their non-involvement are explored as parents may have recommendations that could assist the schools in revising their approach towards teacher-parent involvement.

Parents and grandparents who have never graduated from high school or possibly were never attendees at a high school feel incompetent and insecure as they do not have the skill set to assist with homework and also feel intimated by educators (Finders \& Lewis 1994 , Mji \& Mbinda 2005).

Mji and Mbinda (2005) commented that in terms of content knowledge parents cannot be of assistance because they do not possess the necessary education and find it challenging to understand what was done at school. In addition, language barriers are also very real as the participants acknowledged that the schooling is in English and many parents are not fluent in English as Zulu is their native language.

Voices of parents need to be heard. They may not be responding to requests and invites from the school. However, the lack of involvement could be because of time constraints, lack of confidence in engaging with educators, transport 
challenge, money and health challenges. Reasons for lack of parent involvement should be explored and appropriate interventions implemented which accommodates all the stakeholders.

The following statement by one of the participants illustrates the reality and the frustration of the members of the SMT but it is not helpful in addressing the problem as it is a discourse of blame:

'The lack of control by parents is our major concern, and is another challenge that makes learners to simply relax at home and come back to school without doing their homework. The learners whom we teach live with grandparents who do not have the capacity to exercise strong discipline on their grandchildren. This lack of discipline causes learners to avoid doing schoolwork and so they keep on failing since they do not allocate time to study.' (M, 2015)

One of the participants contended that for a child to do well at school one should think of a three-legged pot. The three legs symbolise the learner, the educator and the parent. If one of them does not participate, things will not go well.

Over three decades ago, Lareau (1987) pointed out that parents from disadvantaged backgrounds have limited economic resources and educational skills to fully participate in their children's education in 'traditional' ways. Lareau argued that efforts should be made to ensure that they, the parents, 'feel welcome'. The same holds for parents who are poor and lack formal education within the South African schooling system.

\section{Concluding remarks and suggested interventions}

The results have indicated that for learners to perform, socio-economic issues have to be addressed.

Schools should explore the option of a social compact with community-based non-government organisations, churches, sports organisation's learners and parents in the areas where schools are and learners reside. Intervening at a local level is not going to address the national issues of inequality, poverty and unemployment but certain local interventions could ease the challenges at the community level and assist in learners performing better.

The SMT indicated that the interventions that they had put into place, such as extra classes and winter schools during vacation time, to reduce underperformance was not successful.

Parents also did not attend meetings at which feedback on performance was provided and also to inform them of the additional learning opportunities to increase success. It is a vicious circle and research needs to be conducted to have the voice of parents heard in planning these interventions. It may even be possible for parents to 'supervise' at the interventions at times that are suitable for them. Supervision could include assisting with meals or conducting basic support services that will lead to them to not feel an 'uneducated' guest at the schools but legitimate stakeholders.

One of the schools had implemented an intervention programme whereby they assisted learners with food parcels. As one of the participants stated:

'The school also assists those learners who come from poor families with food parcels so that they are able to concentrate in class and hence are able to face the challenges of coping with schoolwork like doing their homework and assignments.' (2015)

The initiative was taken by the SMT to improve learner performance because their school is not part of the government nutrition programme even though attending learners were from poor families where food insecurity was a reality.

There is an opportunity for schools to explore how parents could get involved in the hunger alleviation and other programmes. Research conducted by Delgado-Gaitin (1991) has indicated that parents who are actively involved in their children's schooling have recognised that their involvement is fundamental to their children being successful learners. Parents from communities such as where the current research was conducted often assume that teachers are responsible for their children's success. Schools need to find ways to encourage parents to be involved. In addition, the parents need to be 'empowered' to believe that even if they themselves lack formal education being involved and showing an interest in their children's school lives is important for academic success.

The SMTs should make themselves available to attend workshops and training which empower them as leaders. It is imperative to ensure that the training they attend focuses on issues related to women leaders in the workplace.

Schools could also form partnerships with various community organisations and universities that would assist with the training and also provide counsellors who are prepared to voluntarily provide counselling services.

Research has indicated that poverty is not the single factor or a stand-alone reason for poor performance (Bayat, Louw \& Rena 2014; Lacour \& Tissington 2011).

However, there is no doubt that school performance is impacted by factors that have emerged from this research. In our opinion, one cannot underestimate the role of poverty in underperformance, but one also cannot assume that because of poverty there are no interventions that could be successfully implemented in assisting learners to learn and perform.

There is no overnight solution and while we agree that the issues of inequality, unemployment, patriarchy and poverty have to be addressed, it is possible that interventions 
that are based on context and include all stakeholders could be successful in addressing the needs of individual schools.

\section{Acknowledgements Competing interests}

The authors have declared that no competing interests exist.

\section{Authors' contributions}

C.P. contributed $80 \%$ to the publication, $100 \%$ of the original data and $20 \%$ of the article was contributed by N.Z.

\section{Funding information}

This research received no specific grant from any funding agency in the public, commercial or not-for-profit sectors.

\section{Data availability statement}

Data sharing is not applicable to this article as no new data were created or analysed in this study.

\section{Disclaimer}

The views reflected in this article are those of the authors and not the institutions they are affiliated with.

\section{References}

Bayat, A., Louw, W. \& Rena, R., 2014a, 'Investigating the confluence of factor impacting on underperformance at selected secondary schools in the Western Cape, South Africa', International Journal of Education Science 7(1), 41-55. https://doi.org/10.1080/09751122.2014.11890168

Bayat, A., Louw, W. \& Rena, R., 2014b, 'The impact of socio-economic factors on the performance of selected high school learners in the Western Cape Province, South Africa', Journal of Human Ecology 45(3), 183-196. https://doi.org/10.1080 109709274.2014.11906692

Braun, V. \& Clarke, V., 2006, 'Using thematic analysis in psychology', Qualitative ResearchinPsychology3(2), 77-101.https://doi.org/10.1191/1478088706qp063oa

Burman, E., 1994, 'Feminist research', in P. Bannister, E. Burman, I. Parker, M. Taylor \& C. Tindall (eds.), Qualitative methods in psychology: A research guide, pp. 121-141, McGraw-Hill Education, New York.

Chikulo, B.C., 2015, 'An exploratory study into the Menstrual Hygiene Management amongst rural high girls in Northwest Province, South Africa', Africa Population Studies 29(2). https://doi.org/10.11564/29-2-777

Chisholm, L., 2011, 'The challenge of South African schooling: Dimensions, targets and initiatives', in Institute for Justice and Reconciliation IJR (ed.). Transformation audit: From inequality to inclusive growth, pp. 50-57, Institute for Justice and Reconciliation, Cape Town.
Creswell, J.W., 1994, Research design: Qualitative and quantitative approaches, Sage, London.

Creswell, J.W., 2003, Research design. Qualitative, quantitative, and mixed methods approaches, 2nd edn., Sage, Thousand Oaks, CA.

Delgado-Gaitin, C., 1991, 'Involving parents in the school: A process of empowerment', American Journal of Education 100(1), 20-46. https://doi.org/10.1086/444003

De Marrais, K. \& Lapan, S.D., 2004, Foundations for research methods of inquiry in education and the social sciences, Lawrence Erlbaum Associates Publishers, London.

Department of Basic Education, 2013, Report on the Annual National Assessment of 2013, Grades 1 to 6 \& 9, Department of Basic Education, Pretoria.

Dimmitt, C., 2003, 'Transforming school counselling practice through collaboration and the use of data: A study of academic failure in high school', Professional School Counselling 6(5), 340-349.

Finders, M. \& Lewis, C., 1994, 'Why some parents don't come to school', Educational Leadership 51(8), 50-54.

Harper, B., Ogbonnaya, I.N. \& McCullough, K.C., 2018, 'The effect of intimate partner violence on the psychosocial development of toddlers', Journal of Interpersonal Violence 33, 2512-2536. https://doi.org/10.1177/0886260516628286

Lacour, M. \& Tissington, L.D., 2011, 'The effect of poverty on academic achievement', Education Research and Reviews 6(7), 522-527.

Lareau, A., 1987, 'Social class differences in family - School relationships: The importance of cultural capital', Sociology of Education 60(April), 73-85.

Louis, S., Dretzke, B. \& Wahlstrom, K., 2010, 'How does leadership affect student achievement? Results from a national US survey', School Effectiveness and Improvement 21(3), 315-336. https://doi.org/10.1080/09243453.2010. 486586

Malahlela, K.M. \& Chireshe, R., 2013, 'Educators' perceptions of the effects of teenage pregnancy on the behaviour of the learners in South African secondary schools: pregnancy on the behaviour of the learners in South African secondary schools:
Implications for teacher training', Journal of Social Sciences 37(2), 137-148. Implications for teacher training', Journal of Social
https://doi.org/10.1080/09718923.2013.11893212

Mji, A. \& Mbinda, Z., 2005, 'Exploring high school science students' perceptions of parental involvement in their education', Psychological Reports 21(1), 335-338.

Mphale, L.M. \& Mhlauli, M.B., 2014, 'An investigation on students' academic performance for junior secondary schools in Botswana', European Journal of Educational Research 3(3), 111-127. https://doi.org/10.12973/eu-jer.3.3.111

Ndlovu, T., 2018, MEC concerned about teen pregnancy rates, viewed 25 September 2019, from www.zululandobserver.co.za/1615942/mec-concerned-high-teenpregnancy-rates/.

Newlin, M., Reynold, S. \& Nombutho, M., 2017, 'Children from child headed households: Understanding challenges that affect in their academic pursuits', Journal of Human Ecology 54(3), 158-153. https://doi.org/10.1080/09709274.20 16.11906998

Setlhodi-Mohapi, I. \& Lebeloane, L., 2014, 'The role of school management teams in underperforming schools: A matter of values', Mediterranean Journal of Social Sciences 5(3), 475

Sommer, M., Ackatia-Armah, N., Connolly, S. \& Smiles, D., 2014, 'Comparison of the menstruation and education experiences of girls in Tanzania, Ghana, Cambodia and Ethiopia', Compare: A Journal of Comparative and International Education 45(4), 22. https://doi.org/10.1080/03057925.2013.871399

South Africa, 1996, Schools Act 84 of 1996, viewed from https://www.gov.za/sites/ default/files/gcis_document/201409/act84of1996.pdf.

South Africa, 2018, General Household Survey, viewed from www.statssa.gov.za/ Publications/P0318/03182018/.

South African Department of Basic Education, 2018, 2018 National senior certificate results school performance report, viewed 25 September 2019, from http://www. ecexams.co.za/2018_Nov_Exam_Results/NCS\%20School $20 \%$ /.

Statistics South Africa, 2015, Media release: Survey of activities of young people, viewed 25 September 2019, from www.statssa.gov.za/publications/P02122015/. 